\title{
Physicians' knowledge about pharmacovigilance in Iraq
}

Muhannad RMS ${ }^{1}$, Arwa YA ${ }^{1}$, Omer QBA ${ }^{2 *}$, Ramadan ME $^{3}$ and Jaafer M. Kurmanji ${ }^{4}$

${ }^{1}$ Department of Pharmacy, Al-Rasheed University College, Baghdad - Iraq

${ }^{2}$ Department of Clinical Pharmacy, College of Pharmacy, University of Duhok, Duhok- Kurdistan Region, Iraq

${ }^{3}$ Department of Pharmacy Practice, Kulliyyah of Pharmacy, International Islamic University of Malaysia, Malaysia

${ }^{4}$ Israa university college, Pharmacy department, Baghdad-Iraq

\begin{abstract}
Background: Pharmacovigilance plays an essential role in the reduction of adverse drugs reaction (ADRs), thus the evolution and growth of this science are critical for effective and safe clinical practice.
\end{abstract}

Aim: This study will evaluate doctors' attitudes, barriers and factors encouraging toward ADRs reporting.

Methods: A cross-sectional prospective study has been conducted. It was a psychometric evaluation assessment using a previously modified questionnaire.

Results: The majority of the surveyed doctors $(78 \%)$ believed that reporting adverse drug reactions (ADRs) is part of their duty, and monitoring drug safety is also important (96\%). The study findings revealed that about $68 \%$ of the doctors felt that they did not have sufficient clinical knowledge to detect ADRs. Nearly two-third of the doctor's agreed that they are not convinced that the ADRs are caused by the drug. This study show that an association between doctors knowledge about ADRs detection and the number of patient seen by day, as the number of patient increased the doctors knowledge about ADRs improved.

Recommendations: Special and direct educational programs, along with continued promotion, could help to enhance the involvement of physicians in ADR reporting and pharmacovigilance activities and help to reduce misconceptions and other logistic barriers to ADR reporting. Further studies with large populations are needed for a better understanding of the actual deterrents which prevent private clinic doctors from reporting ADRs.

Keywords: Pharmacovigilance; Iraq; Physician; Attitude; Knowledge; Barriers; ADRs

\section{Introduction}

Adverse drug reactions (ADRs) are a major cause of patient related morbidity and mortality [1], and they are associated with a high prevalence of hospital admission reaching about $6.5 \%$ as well as a considerable economic burden; in which around $£ 466$ million was reported as an annual total cost for drug related admissions in the United Kingdom [2]. Thus reporting of ADRs is considered to be an important step in maintaining and achieving a safe drug therapy use. Most countries developed their national pharmacovigilance systems after the thalidomide disaster in 1960s [3].

The World Health Organization (WHO) has established the definition of pharmacovigilance as "the science and activities relating to the detection, assessment, understanding and prevention of adverse effects or any other possible drug-related problems" [4]. Pharmacovigilance plays an essential role in the reduction of ADRs, thus the evolution and growth of this science are critical for effective and safe clinical practice.

However, their strength is tightly connected to the actual reporting rate by health care professionals [5]. All sectors of the healthcare system would need to be involved in the reporting process, such as public and private hospitals, general practitioners, nurses, retail dispensaries, and pharmacists. In the general use of medicine, practitioners should take the responsibility to have adequate knowledge and to report unwanted adverse events (both expected and unexpected) [6].

Doctors were found to have an important role in ADRs detection, and constitute a potentially valuable source for spontaneous ADRs reports [7]. However, sometimes the spontaneous reporting system may experience several hinders resulting in under-reporting of ADRs. The low reporting rate of ADRs is a main intrinsic problem.
In a big step forward, on $3^{\text {rd }}$ November 2010, Iraq became the 102 nd country to become a full member of the WHO Program for International Drug Monitoring, after fulfilling all the required conditions [8]. Since that time, no studies have assessed doctor's knowledge and attitudes toward ADRs reporting at the hospital and community settings in Iraq. Our study was in the unique position to study doctors' attitudes, barriers and factors encouraging toward ADRs reporting after the initiation of the national ADRs reporting center.

\section{Methods}

A cross-sectional prospective study has been conducted. It was a psychometric evaluation assessment using a previously modified and developed questionnaire [9-13] .The researchers have done some amendments on the mentioned tool to fit the actual physician practice in private out-patient clinics in Baghdad. The questionnaire examined the attitudes, perception, and barriers to ADR reporting among healthcare professionals. Cluster sampling method was conducted in this study, the investigators have targeted private clinics in several districts in Baghdad with different socioeconomic levels including (Harithiya, Birut square, Sader city, Adamiya, and Nafaq shurta). The final

*Corresponding author: Omer QB Allela, Clinical Pharmacy, College of Pharmacy, University of Duhok, Duhok- Kurdistan Region, Iraq, Tel: 964062722 2292; E-mail: omarallela@yahoo.com

Received: June 13, 2016; Accepted June 20, 2016; Published June 28, 2016

Citation: Muhannad RMS, Arwa YA, Omer QBA, Ramadan ME, Kurmanji JM (2016) Psychometric Evaluation of Physician toward Pharmacovigilance Practice in Iraq. J Pharmacovigilance 4: 214. doi:10.4172/2329-6887.1000214

Copyright: (c) 2016 Muhannad RMS, et al. This is an open-access article distributed under the terms of the Creative Commons Attribution License, which permits unrestricted use, distribution, and reproduction in any medium, provided the original author and source are credited. 
questionnaire was 6 pages in length classified into the following areas: the first part consisted of 15 items, which covered the demographic characteristics of the respondents. It does include general questions to verify the extent of the doctors' knowledge about the Iraqi ADR reporting system and the doctors' behavior. The second part comprises of 14 items exploring the doctors' attitude to ADRs reporting. It is looking at the factors that either positively or negatively affected the doctors' attitude. These items were constructed as a series of statements and the doctors were asked to indicate their agreement or disagreement using a 5-point Likert scale format (1="strongly agree," $2=$ "agree," 3 = "neutral," 4 = "disagree," and 5 = "strongly disagree).

The third part of the survey contained 15 items, which explored the barriers to report an ADR. These questions also used a 5-point Likert scale. The fourth part of the questionnaire consisted of 7 items, which aimed to identify the factors that might encourage and motivate doctors to report ADRs. Similar to the above stated parts, these items were also framed in a 5-point Likert rating scale.

\section{Results}

\section{Respondent's characteristics}

Over the study period (two months; February and March 2016), the surveyed questionnaire were delivered to 120 out-patient clinics, only 70 doctors filled the questionnaire. However, 20 forms were neglected for missing data. Therefore, merely 50 questionnaires were considered for this investigation with a useful response rate of $41 \%$. Males accounted for 78\% (39) of respondents. More than one-third of surveyed doctors don't hold any post-graduate degree. Nearly twothird of the doctors considers the British National Formulary (BNF) as the main source of drug information.

A considerable proportion of the respondents $(11 ; 22 \%)$ claimed that they know what the term "pharmacovigilance" is stand for. Nevertheless, around $81 \%$ (9) of them were unable to give a correct definition (Table 1).

\section{Attitude and behaviors}

$78 \%$ of doctors believed that reporting adverse drug reactions (ADRs) is part of their duty, and monitoring drug safety is also important $96 \%$ (48).

More than $90 \%$ of the physicians think that they should only report ADRs leading to hospitalizations, life threating conditions, congenital abnormalities, persistent disability or incapacity.

A large percentage $(92 \%)$ of the respondents reflects that it's important to discuss ADRs with the pharmacist and/or an academician trained in this field (Table 2).

\section{Barriers to ADRs reporting}

Around three-quarter of the respondents stated that the unavailability of the reporting form and the unawareness of the address where the reporting form should be sent are reasons for under-reporting.

The study findings revealed that about $68 \%$ of the doctors felt that they did not have sufficient clinical knowledge to detect ADRs. Nearly two-third of the doctor's agreed that they are not convinced that the ADRs are caused by the drug (Table 3 ).

This study show that an association between doctors knowledge about ADRs detection and the number of patient seen by day, as the number of patient increased the doctors knowledge about ADRs improved (Table 4).

\begin{tabular}{|c|c|c|}
\hline Sociodemographic & $\mathbf{N}$ & $\%$ \\
\hline \multicolumn{3}{|c|}{ Gender } \\
\hline Male & 39 & 78 \\
\hline Female & 11 & 22 \\
\hline \multicolumn{3}{|c|}{ Age } \\
\hline $31-40$ & 13 & 26 \\
\hline $41-50$ & 20 & 40 \\
\hline$\geq 51$ & 17 & 34 \\
\hline \multicolumn{3}{|c|}{ Post-graduate } \\
\hline Yes & 38 & 76 \\
\hline No & 12 & 24 \\
\hline \multicolumn{3}{|c|}{ Length of practice } \\
\hline $0-10$ & 14 & 28 \\
\hline $11-20$ & 19 & 38 \\
\hline $21-30$ & 11 & 22 \\
\hline $31-40$ & 5 & 10 \\
\hline $40<$ & 1 & 2 \\
\hline \multicolumn{3}{|c|}{ No. patients per days } \\
\hline $0-10$ & 26 & 52 \\
\hline $11-20$ & 19 & 38 \\
\hline $20<$ & 5 & 9 \\
\hline \multicolumn{3}{|c|}{ No. participations in scientific events per year } \\
\hline None & 2 & 4 \\
\hline 1-3 per year & 34 & 68 \\
\hline 4-7 per year & 7 & 14 \\
\hline$>7$ per year & 7 & 14 \\
\hline \multicolumn{3}{|c|}{ No. of ADR reported in the last year } \\
\hline Never & 43 & 86 \\
\hline One & 1 & 2 \\
\hline Two & 3 & 6 \\
\hline Three & 3 & 6 \\
\hline \multicolumn{3}{|c|}{ University of graduation } \\
\hline University of Baghdad & 21 & 42 \\
\hline Al-Mustansiriya University & 14 & 28 \\
\hline University of Mosul & 6 & 12 \\
\hline University of Tikrit & 2 & 4 \\
\hline University of Anbar & 2 & 4 \\
\hline University of Basrah & 4 & 8 \\
\hline Al-Nahrain University & 1 & 2 \\
\hline
\end{tabular}

Table 1: Physician's characteristics $(\mathrm{N}=50)$

\section{Factors encouraging reporting of ADRs}

Only $28 \%$ of the doctors disagreed that receiving incentives would encourage them to report. Approximately three-quarter (74\%) of respondents indicated that receiving feedback from the relevant authorities would be an important factor, which would motivate them to report ADRs.

More two-third (70\%) of them claimed that simplifying the ADR reporting process would be a great encouragement to actively participate in ADR reporting. (44\%) of physician think that they would report if there is an obligation to do so. Seeing their colleagues doing so would encourage them to report (42\%) of them agreed. The doctors think Publication such as in the medical journal will give them more attention about pharmacovigilance system $(66 \%)$

\section{Discussion}

Underreporting of ADRs is a major threat to the success of pharmacovigilance program. Various factors have been found to be responsible for underreporting of ADRs by doctors. These factors are 
Citation: Muhannad RMS, Arwa YA, Omer QBA, Ramadan ME, Kurmanji JM (2016) Psychometric Evaluation of Physician toward Pharmacovigilance Practice in Iraq. J Pharmacovigilance 4: 214. doi:10.4172/2329-6887.1000214

Page 3 of 5

\begin{tabular}{|c|c|c|c|c|c|c|}
\hline & \multirow[b]{2}{*}{ Survey Question } & \multicolumn{5}{|c|}{ Responses n (\%) } \\
\hline & & Strongly Agree & Agree & Neutral & Disagree & $\begin{array}{l}\text { Strongly } \\
\text { Disagree }\end{array}$ \\
\hline 1. & Reporting of ADRs is part of a doctor duty. & $8(16)$ & $31(62)$ & $6(13)$ & $4(8)$ & $1(2)$ \\
\hline 2. & I believe that monitoring drug safety is important. & $24(48)$ & $24(48)$ & $2(4)$ & 0 & 0 \\
\hline 3. & $\begin{array}{c}\text { It is necessary to be confirmed that an ADR is related to a particular } \\
\text { drug before reporting. }\end{array}$ & $9(18)$ & $31(62)$ & $6(12)$ & $4(8)$ & 0 \\
\hline 4. & $\begin{array}{l}\text { It is not necessary to report those ADRs which are related to OTC } \\
\text { products dispensed in my pharmacy }\end{array}$ & $1(2)$ & $8(16)$ & $12(24)$ & $23(46)$ & $6(12)$ \\
\hline 5. & It is important to report ADRs leading to hospitalization. & $23(46)$ & $22(44)$ & $3(6)$ & $2(4)$ & 0 \\
\hline 6. & It is important to report ADRs leading to a life threatening situation. & $32(64)$ & $17(34)$ & 0 & $1(2)$ & 0 \\
\hline 7. & It is important to report ADRs leading to congenital abnormality & $35(70)$ & $14(28)$ & 0 & $1(2)$ & 0 \\
\hline 8. & $\begin{array}{l}\text { It is important to report ADRs leading to persistence disability or in } \\
\text { capacity. }\end{array}$ & $31(62)$ & $3(6)$ & $3(6)$ & $1(2)$ & 0 \\
\hline 9. & $\begin{array}{l}\text { It is important to report ADRs in order to answer the questions that } \\
\text { may arise in my practice. }\end{array}$ & $14(28)$ & $27(54)$ & $6(12)$ & $3(6)$ & 0 \\
\hline 10. & $\begin{array}{c}\text { Reporting of ADRs is important to show patients that their concerns } \\
\text { are taken seriously. }\end{array}$ & $9(18)$ & $31(62)$ & $7(14)$ & $2(4)$ & $1(2)$ \\
\hline 11. & $\begin{array}{c}\text { I feel annual reports issued by MADRAC concerning monitoring and } \\
\text { reporting of ADRs are useful. }\end{array}$ & $4(8)$ & $27(54)$ & $13(26)$ & $4(8)$ & $2(4)$ \\
\hline 12. & Consulting the physician is important before reporting an ADR. & $5(10)$ & $38(76)$ & $5(10)$ & $1(2)$ & $1(2)$ \\
\hline 13. & $\begin{array}{l}\text { Moving the responsibility of } \\
\text { Pharmacovigilance scheme to pharmaceutical industry o academy } \\
\text { will improve ADRs reporting. }\end{array}$ & $6(12)$ & $22(44)$ & $12(24)$ & $7(14)$ & $3(6)$ \\
\hline 14. & $\begin{array}{l}\text { It is important to discuss ADRs with a physician and/or an } \\
\text { academician trained in this field }\end{array}$ & $8(16)$ & $38(76)$ & $1(2)$ & $2(4)$ & $1(2)$ \\
\hline
\end{tabular}

Table 2: Respond of Attitudes toward ADRs reporting.

\begin{tabular}{|c|c|c|c|c|c|c|}
\hline & \multirow[b]{2}{*}{ Survey Question } & \multicolumn{5}{|c|}{ Responses n (\%) } \\
\hline & & Strongly Agree & Agree & Neutral & Disagree & $\begin{array}{l}\text { Strongly } \\
\text { Disagree }\end{array}$ \\
\hline 1. & Reporting forms are not available. & $31(62)$ & $8(16)$ & $5(10)$ & $2(4)$ & $4(8)$ \\
\hline 2. & $\begin{array}{l}\text { I do not know the address where these reports should be } \\
\text { sent. }\end{array}$ & $28(56)$ & $8(16)$ & $3(6)$ & $2(4)$ & $9(18)$ \\
\hline 3. & The reporting form is too complicated to be filled. & $13(26)$ & $5(10)$ & $13(26)$ & $4(8)$ & $15(30)$ \\
\hline 4. & Reporting is time-consuming. & $14(28)$ & $5(10)$ & $6(12)$ & $8(16)$ & $17(34)$ \\
\hline 5. & All serious ADRs are detected before registration. & $13(26)$ & $6(12)$ & $11(22)$ & $5(10)$ & $15(30)$ \\
\hline 6. & $\begin{array}{c}\text { I do not report ADRs because I want to publish the case by } \\
\text { myself. }\end{array}$ & $4(8)$ & $1(2)$ & $5(10)$ & $12(24)$ & $28(56)$ \\
\hline 7. & $\begin{array}{l}\text { I am not convinced about the confidential handling of the } \\
\text { report. }\end{array}$ & $9(18)$ & $3(6)$ & $10(20)$ & $8(16)$ & $20(40)$ \\
\hline 8. & I fear to harm the confidence of my patients. & $1(2)$ & $11(22)$ & $10(20)$ & $10(20)$ & $18(36)$ \\
\hline 9. & I find it difficult to admit that the patient has been harmed. & $8(16)$ & $2(4)$ & $7(14)$ & $10(20)$ & $23(46)$ \\
\hline 10. & I fear legal liability of the reported ADR. & $13(26)$ & $3(6)$ & $8(16)$ & $6(12)$ & $20(40)$ \\
\hline 11. & I am not motivated to report. & $9(18)$ & $7(14)$ & $6(12)$ & $6(12)$ & $22(44)$ \\
\hline 12. & I have insufficient clinical knowledge in detecting ADRs. & $4(8)$ & $4(8)$ & $8(16)$ & $7(14)$ & $27(54)$ \\
\hline 13. & I do not know how to report an ADR. & $11(22)$ & $5(10)$ & $7(14)$ & $6(12)$ & $21(42)$ \\
\hline 14. & $\begin{array}{c}\text { Decentralization of Pharmacovigilance center (i.e. multiple } \\
\text { centers) would increase the rate and quality of reports } \\
\text { among the retail pharmacists. }\end{array}$ & $20(40)$ & $6(12)$ & $14(28)$ & $5(10)$ & $5(10)$ \\
\hline 15. & I am not convinced that the ADR is caused by the drug. & $4(8)$ & $6(12)$ & $10(20)$ & $30(60)$ & $30(60)$ \\
\hline
\end{tabular}

Table 3: Barrier to ADRs reporting.

\begin{tabular}{|c|c|c|c|c|}
\hline \multirow{2}{*}{ Variables } & \multicolumn{3}{|c|}{ Physician's n (\%) } & \multirow{2}{*}{$\mathrm{P}$} \\
\hline & $\begin{array}{c}\leq 10 \text { patient } / \\
\text { day }\end{array}$ & $\begin{array}{c}11-21 \\
\text { patient/day }\end{array}$ & $\begin{array}{c}>20 \\
\text { patient/day }\end{array}$ & \\
\hline & $26(52)$ & $19(38)$ & $5(10)$ & \\
\hline \multicolumn{5}{|c|}{ I have insufficient clinical knowledge in detecting ADR } \\
\hline Disagree & $13(50)$ & $17(89.5)$ & $4(80)$ & 0.020 \\
\hline Neutral & $8(30.8)$ & $0(0.0)$ & $0(0.0)$ & \\
\hline Agree & $5(19.2)$ & $2(10.5)$ & $1(20)$ & \\
\hline
\end{tabular}

Table 4: Association between the number of patients seen by the respondent physicians and some barriers to report adverse drug reaction $(N=50)$. mainly related with the barriers and attitudes [14]. Very few studies have been conducted to find out these factors in Iraqi doctors. Therefore, the present study was performed to investigate the knowledge and attitudes of doctors to ADR reporting in outpatient clinics. The results reflect upon the lack of awareness of participant doctors about the existence of ADR reporting system, which would ultimately affect the reporting. Similar observations were also reported in other studies $[15,16]$. The deficits in the spontaneous reporting system can be meaningfully reduced if the doctors are aware of the importance of reporting ADRs. Although majority of the doctors felt that ADR reporting is a professional obligation, they are more motivated to report serious 
ADRs [15]. Personal discussions and awareness programs will help to remove misconceptions and modify the attitudes of doctors, whereby ADR reporting is perceived as an integral part of clinical practice.

There was an obvious underestimation for the magnitude of ADRs related to OTC products among the Iraqi physicians. Indeed, the pharmacovigilance concepts encourage the reporting of all suspected, even non-serious and common ADRs related to all type of medicines including OTC products [17].

Marketing approval is given to a product after phase III clinical trial. Many times, serious and unusual ADRs are not identified during phase III trial, but are detected later on when the drug is available for use to general population. Inability of the respondents to identify the serious risk of newly marketed drug is an alarming situation and needs to be addressed urgently. As the Iraqi market is flooded with the arrival of newer and newer drugs, delayed detection of serious ADR may prove to be disastrous to the patients and the society at large. The findings of our study are indicative of the inadequate risk for newly marketed drugs as well as OTC products. Probably, this may be attributed to the absence of pharmacovigilance papers in the undergraduate curriculum for medical school in Iraq. Thirty eight percent of the doctors think that ADRs reporting is time consuming process. This may negatively affect the reporting rate among Iraqi doctors. Fearing legal liability and financial incentives had a little influence on the respondents. These findings suggest that underreporting of ADRs is related to obvious gaps in knowledge and negative perception, which is also pointed out in other studies [17-19]. Interestingly, fear is a discouraging factor for majority of the doctors to report an ADR.

Ignorance of the address where the ADR report should be sent and unavailability of the reporting form were nominated as the most significant barriers prevent doctors from reporting ADRs. These indicators should push the regulatory authorities into action to make their addresses identified as well as to enhance the availability of the form. The inability to define the concept of pharmacovigilance among the vast majority of respondents might be attributed to a lack of proper exposure during the earlier stages of their undergraduate medical education and the likelihood of poor publicity of the concept among the respondents by the relevant authorities.

Although a substantial number of the respondents considered decentralization of the pharmacovigilance center as a significant facilitator of the ADR reporting process. These findings should be interpreted with caution as almost all of the respondents were unfamiliar with existing pharmacovigilance systems in the country. The literature reported that the decentralization of the pharmacovigilance system has been adopted in some developed countries [20,21] A previous study carried out by Eland et al in 1999 showed that the number of reports from healthcare professionals increased by approximately $75 \%$ after the decentralization of the reporting system [21].

\section{Conclusion}

The study has generated important data about the characteristics, attitudes, barrier and factors of doctors in Iraq, which could be useful to further support the development and successful implementation of strategies to improve the involvement in private clinic doctors in ADR reporting activities. As the study findings demonstrate, Continuous medical Education is one of the possible and successful ways to motivate and encourage doctors to be involved in ADR reporting and pharmacovigilance activities. Special and direct educational programs, along with continued promotion, could help to enhance the involvement of physicians in ADR reporting and pharmacovigilance activities and help to reduce misconceptions and other logistic barriers to ADR reporting. Further studies with large populations are needed for a better understanding of the actual deterrents which prevent private clinic doctors from reporting ADRs.

\section{Recommendation}

In order to enhance the pharmacovigilance responsiveness and simplify the reporting process, we recommend making awareness conference for the doctors, that supported by the Iraqi pharmacovigilance center and ministry of health. Improve the reporting process by simplify the delivering of the forms to the doctors and extracting the form from them by special representatives or more easy by email, mobile number and mobile application. Expansion in social media is important to reach the maximum possible number, unfortunately the Facebook page of IPhC we found was ignored and lack updating for a long time ago.

\section{References}

1. Khan SA, Goyal C, Chandel N, Rafi M (2013) Knowledge, attitudes, and practice of doctors to adverse drug reaction reporting in a teaching hospital in India: An observational study. J Nat Sci Biol Med 4: 191-196.

2. Rawlins MD (1986) Spontaneous reporting of adverse drug reactions. Q J Med 59: 531-534.

3. World Health Organization (2002) Some traditional herbal medicines, some mycotoxins, naphthalene and styrene.

4. Eland IA, Belton KJ, van Grootheest AC, Meiners AP, Rawlins MD (1999) Attitudinal survey of voluntary reporting of adverse drug reactions. $\mathrm{Br} \mathrm{J}$ Clin Pharmacol 48: 623-627.

5. Suyagh M, Farah D, Farha RA (2015) Pharmacist's knowledge, practice and attitudes toward pharmacovigilance and adverse drug reactions reporting process. Saudi Pharmaceutical Journal 23: 147-153.

6. Kaboli PJ, Hoth AB, McClimon BJ, Schnipper JL (2006) Clinical pharmacists and inpatient medical care: a systematic review. Arch Intern Med 166: 955-964.

7. Mahmoud MA, Alswaida Y, Alshammari T, Khan TM, Alrasheedy A, et al (2014) Community pharmacist's knowledge, behaviors and experiences about adverse drug reaction reporting in Saudi Arabia. Saudi Pharm J 22: 411-418.

8. de Langen J, van Hunsel F, Passier A, de Jong-van den Berg L, van Grootheest $\mathrm{K}(2008)$ Adverse drug reaction reporting by patients in the Netherlands: three years of experience. Drug Saf 31: 515-524.

9. Elkalmi MMR (2010) Assessment of Knowledge, Attitudes, Perception And Barriers Towards Pharmacovigilance Activities Among Community Pharmacists And Final Year Pharmacy Students In Malaysia.

10. Elkalmi RM, Al-lela OQ, Jamshed SQ (2014) Motivations and Obstacles for Adverse Drug Reactions Reporting among Healthcare Professionals from the Perspective of Lewin's Force Field Analysis Theory: Analytic Approach. Journal of Pharmacovigilance 2:3.

11. Elkalmi RM, Hassali MA, Ibrahim MIM (2011) Impact of educational intervention for improving pharmacist knowledge in adverse drug reactions (ADR) reporting: experience from Malaysia. The Open Drug Safety Journal.

12. Elkalmi RM, Hassali MA, Ibrahim MI, Jamshed SQ, Al-Lela OQ (2014) Community pharmacists' attitudes, perceptions, and barriers toward adverse drug reaction reporting in Malaysia: a quantitative insight. Journal of patient safety 10: 81-87.

13. Elkalmi RM, Hassali MA, Ibrahim MI, Widodo RT, Efan QM, et al. (2011) Pharmacy students' knowledge and perceptions about pharmacovigilance in Malaysian public universities. Am J Pharm Educ 75: 96.

14. Oshikoya KA, Awobusuyi JO (2009) Perceptions of doctors to adverse drug reaction reporting in a teaching hospital in Lagos, Nigeria. BMC Clin Pharmacol 9: 14.

15. Belton KJ (1997) Attitude survey of adverse drug-reaction reporting by health care professionals across the European Union. The European Pharmacovigilance Research Group. Eur J Clin Pharmacol 52: 423-427.

16. Li Q, Zhang SM, Chen HT, Fang SP, Yu X, et al. (2004) Awareness and attitudes of healthcare professionals in Wuhan, China to the reporting of adverse drug reactions. Chin Med J (Engl) 117: 856-861. 
Citation: Muhannad RMS, Arwa YA, Omer QBA, Ramadan ME, Kurmanji JM (2016) Psychometric Evaluation of Physician toward Pharmacovigilance Practice in Iraq. J Pharmacovigilance 4: 214. doi:10.4172/2329-6887.1000214

Page 5 of 5

17. Priyadharsini R, Surendiran A, Adithan C, Sreenivasan S, Sahoo FK (2011) A study of adverse drug reactions in pediatric patients. J Pharmacol Pharmacother 2: 277-280.

18. Lopez-Gonzalez E, Herdeiro MT, Figueiras A (2009) Determinants of underreporting of adverse drug reactions: a systematic review. Drug Saf 32: 19-31.

19. Hasford J, Goettler M, Munter KH, Müller-Oerlinghausen B (2002) Physicians' knowledge and attitudes regarding the spontaneous reporting system for adverse drug reactions. J Clin Epidemiol 55: 945-950.
20. Edwards IR, Olsson S, Lindquist M, Hugman B (2005) Global drug surveillance: the WHO programme for international drug monitoring. Pharmacoepidemiology 161-183.

21. Begaud B (1992) Pharmacovigilance in France: a decentralized approach. Drug epidemiology and post-marketing surveillance 224: $39-42$. 